\title{
Microstructural Analysis of Crept Martensitic Steels
}

\author{
Srinivasan Swaminathan ${ }^{1}$, Mallikarjun Karadge ${ }^{2}$, T. Vishwanath ${ }^{1}$ and Ramkumar Oruganti ${ }^{1}$ \\ ${ }^{1}$ General Electric - Global Research, Whitefield, Bangalore-560066, Karnataka, India \\ ${ }^{2}$ General Electric - Global Research, Niskayuna, NY- 12309, United States of America
}

The role played by different length-scale microstructural features on the creep deformation of ferritic martensitic steels is documented. Emphasis has been placed on the role of additive contributions of blocks, laths and/or nano-sized precipitates on creep behavior elucidated through modeling.

Over the past two decades, considerable focus has been placed on ferritic martensitic steels as materials for high temperature steam turbine applications. The rationale for the choice of ferritic martensitic steels lies in the fact that their microstructures can be tailored to be stable at higher temperatures and intermediate stresses. These steels are subjected to creep deformation during service. Here, we attempt to model the creep behavior by studying and empirically modeling microstructure degradation.

A review of microstructural features desired for resisting creep deformation in these steels has been presented in reference 1 . The hierarchy of ferritic martensitic steels down to nanoscale consists of: prior austentic grain boundaries, packet boundaries, block boundaries, lath boundaries (in that order). Interspersed on and within these boundaries are various precipitates like $\mathrm{M}_{23} \mathrm{C}_{6}, \mathrm{MX}, \mathrm{M}_{2} \mathrm{X}$ etc. In this talk, we present with the aid of optical microscopy (OM), orientation imaging microscopy (OIM) and transmission electron microscopy (TEM), microstructural analysis at different length scales of select advanced ferritic martensitic steels subjected to creep deformation. Emphasis has been placed on the role of additive contributions of blocks, laths and/or nano-sized precipitates on creep behavior elucidated through modeling. Microstructural changes occurring as a result of alterations in chemical compositions or processing histories and their influence on creep behavior will also be discussed.

Representative images of blocks from OM and OIM are shown in Figs. 1a) and b), respectively. Figure 1c) shows laths and their boundaries decorated by carbides. The needle shaped MX particles (from TEM analysis) are illustrated in Fig. 1d) while the spherical MX particles are depicted in Fig. 1e). The microstructural features in Fig. 1 have been statistically quantified on different samples subjected to creep deformation over $565^{\circ} \mathrm{C}$ to $649^{\circ} \mathrm{C}$ and a varied stress range. Based on the quantification, empirical relationships have been derived showing creep dependence on various microstructural features. Further, the empirical relations aided in development of a full-fledged continuum damage mechanics model [2].

Based on the microstructure analysis, it was seen that the short-term creep behavior of these steels was controlled by combination of blocks and lath sizes while long-term creep behavior was controlled by MX particle coarsening. Further, empirical relationships developed using parameters derived from microstructural features helped in the understanding of creep behavior, especially that of long-term much more accurately than existing models [3].

\section{References:}

[1] F. Abe, Science and Technology of advanced materials 9 (2008), p. 1 (013002).

[2] R. Oruganti, M. Karadge and S. Swaminathan, Acta Materialia 59 (2011), p. 2145.

[3] The authors wish to acknowledge funding from GE Energy, Materials and Process Engineering 
Department. Intense technical discussions with Robin Schwant (Materials and Process Engineering, GE-Energy) are also acknowledged.
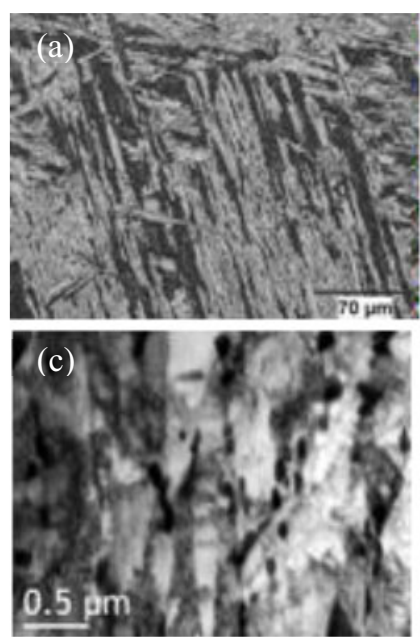
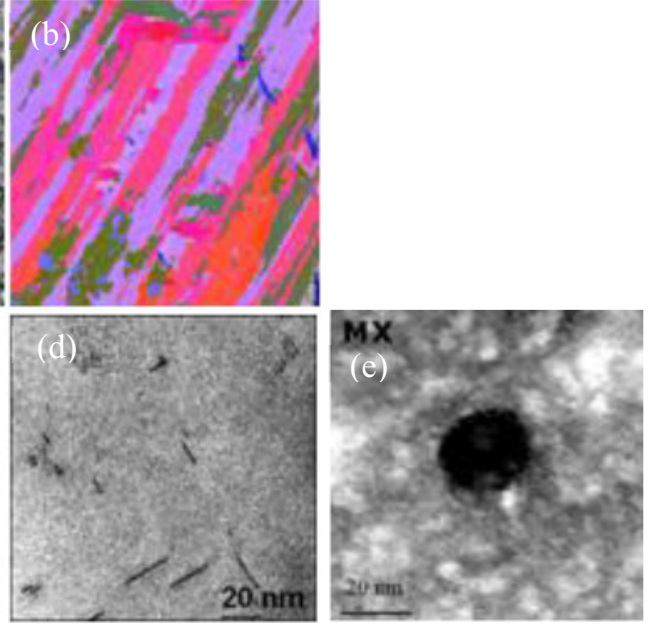

Figure 1: (a) Optical micrograph of blocks, (b) orientation imaging microscopy of blocks and (c) TEM image of laths. (d) and (e) shows MX particles of different morphologies that can be obtained by heat treatment and/or thermo mechanical processing. 